\title{
Concentração de mercúrio e análise histopatológica em músculo, rim e cérebro de peixe-espada (Trichiurus lepturus) coletados na praia de Itaipu, Niterói, Rio de Janeiro, Brasil
}

\author{
Mercury level and histopathologic analysis of muscle, kidney and brain of largehead hairtail \\ (Trichiurus lepturus) collected in Itaipu beach, Niterói, Rio de Janeiro, Brazil
}

\author{
Tatiana Pereira Cardoso ${ }^{\mathrm{I}}$ Eliane Teixeira Mársico ${ }^{\mathrm{II}}$ Renata Jurema Medeiros ${ }^{\mathrm{III}}$ \\ Rogério Tortelly $^{\mathrm{IV}}$ Leila Gatti Sobreiro ${ }^{\mathrm{V}}$
}

\section{RESUMO}

O pescado e seus derivados destacam-se como fonte de exposição e contaminação por metais pesados para o homem. A acumulação do metal mercúrio (Hg) ocorre de forma progressiva através da cadeia trófica e da água sendo o peixe-espada um carnívoro localizado no topo da cadeia alimentar ele pode representar o grau de contaminação da região estudada. Os objetivos neste estudo foram determinar os teores de mercúrio $(\mathrm{Hg})$ e realizar análise histopatológica em órgãos da espécie Trichiurus lepturus em peixes comercializados na região da praia de Itaipu, Niterói - RJ. Foram analisados trinta e um animais, nos quais foram encontrados em musculatura e rim valores médios de $\mathrm{Hg}$ de $0,051 \pm 0,031 \mu \mathrm{g} \mathrm{g}^{-1}$ e 0,006 $00,004 \mu \mathrm{g} \mathrm{g}^{-1}$, respectivamente. No pool de cérebro de todos os animais obteve-se o valor de $0,019 \mu \mathrm{g} \mathrm{g}^{-1}$. Os valores individuais mínimos e máximos de $\mathrm{Hg}$ na musculatura e no rim demonstraram uma ampla dispersão. Nas análises de correlação entre comprimento total e teores de Hg em musculatura, e peso total e teores de Hg em musculatura, foi verificada uma correlação positiva $(r=0,85$ e $r=0,88$ respectivamente) altamente significativa $(P<0,0001)$. Entretanto, na correlação entre peso do rim e os teores de $\mathrm{Hg}$ no mesmo órgão, não foi demonstrada uma correlação significativa $(r=0,24)$ ao nível de confiança de 95\% $(P>0,19)$. Nos testes de comparação múltipla entre os teores médios encontrados em musculatura, rim e cérebro, foi observada uma diferença altamente significativa entre os valores do músculo e do rim, assim como entre os do músculo e do cérebro $(P<0,001$ para ambos). Na comparação entre rim e cérebro, também foi verificada uma diferença significativa ao nivel de $5 \%$ de probabilidade $(P<0,05)$. Na análise histopatológica, foram observadas lesões no rim, caracterizando-se por metaplasias cartilaginosas em alguns exemplares e uma intensa presença de corpos melanomacrofágicos.

Palavras-chave: mercúrio, Peixe-espada, Trichiurus lepturus, histopatologia.

\section{ABSTRACT}

Fish is an important source of heavy metal exposition and contamination for human being. Accumulation of mercury $(\mathrm{Hg})$ in men occurs by chronicle exposition, through the food chain, by ingestion of fish contaminated with mercury. Because of biomagnifications the carnivorous fish that is on the top of the food chain shows a higher concentration of mercury in their tissues and can represent the aquatic environmental contamination. This work aims to establish histopathologic analysis and total mercury concentration in different tissues from thirty-one Trichiurus lepturus, a commercial fish from Itaipu Beach, Niterói, RJ. T. lepturus collected showed mean values of total mercury concentration of $0.051 \pm 0.031 \mu \mathrm{g} \mathrm{g}^{-1}$ and $0.006 \pm 0.004 \mu \mathrm{g} \mathrm{g}^{-1}$, respectively in muscle and kidney tissues. It was also conducted an analysis of mercury concentration from a pool of brain tissue from all individuals $\left(0.019 \mu \mathrm{g} \mathrm{g}^{-1}\right)$. Minimum and maximum mercury values in muscular and kidney tissues showed a wide dispersion. There was a positive correlation between total length and mercury muscular tissue concentration $(R=0.85)$ and between body weight and mercury muscular tissue concentration $(R=0.88)$, both highly significant. No significant correlation $(r=0.24)$ was observed between kidney weight and mercury tissue concentration $(P>0.19)$. In a multiple comparison test

'Programa de Pós-graduação em Higiene Veterinária e Processamento Tecnológico de Produtos de Origem Animal, Faculdade de Medicina Veterinária, Universidade Federal Fluminense (UFF). Rua Vital Brazil Filho, 64, 24230-340, Santa Rosa, Niterói, RJ, Brasil. E-mail: ticapereira@globo.com. Autor para correspondência.

"Departamento de Tecnologia de Alimentos, Faculdade de Medicina Veterinária, UFF, Niterói, RJ, Brasil.

IIIPrograma de Pós-graduação em Vigilância Sanitária, Instituto Nacional de Controle de Qualidade em Saúde, Fundação Oswaldo Cruz (FIOCRUZ), Rio de Janeiro, RJ, Brasil.

IVDepartamento de Patologia, Faculdade de Medicina Veterinária, UFF, Niterói, RJ, Brasil

vepartamento de Medicina Veterinária Coletiva e Saúde Pública, Faculdade de Medicina Veterinária, UFF, Niterói, RJ, Brasil 
among muscle, kidneys and brain mercury tissue concentration, it was observed a highly significant difference between muscle and kidneys $(P<0.001)$, as well as between muscle and brain $(P<0.001)$. Comparison between kidney and brain mercury tissue concentration also showed a significant difference with a probability level of $5 \%(P<0.05)$. Histopathology demonstrated damage in the kidneys (cartilaginous metaplasia in some individuals and a high presence of melanomacrophage centers).

Key words: mercury, largehead hairtail, Trichiurus lepturus, histopathology

\section{INTRODUÇÃO}

Dentre os alimentos, o pescado e seus derivados destacam-se como fonte de exposição e contaminação por metais pesados para o Homem (WHO, 1990; WIENER e SPRY, 1996). Principalmente o metal mercúrio $(\mathrm{Hg})$, que sofre acumulação no organismo desses animais de forma progressiva, através da cadeia trófica e da água (HOFFMAN et al., 2003). Sendo o peixe-espada um carnívoro localizado no topo da cadeia alimentar (MARTINS \& HAIMOVICI, 1997), ele pode representar bem o grau de contaminação da região estudada.

Os principais sintomas observados em seres humanos contaminados caracterizam-se por alterações neurológicas, que podem vir a promover redução do campo visual, ataxia e parestesia, perda de controle motor, tremores musculares, paralisia, deterioração mental e até morte (CARPI, 2001). Nos peixes, além das alterações neurológicas e comportamentais, pode ser detectada alteração tecidual, principalmente nos órgãos e tecidos onde ocorrem as maiores concentrações do Hg. Injúrias e danos teciduais observados em rim e figado sugerem um mecanismo de defesa bastante lento para a eliminação do metilmercúrio ingerido, demonstrando a sensibilidade das células do peixe à exposição ao metal em altas concentrações (MELA et al., 2007).

Este estudo teve como objetivos determinar os níveis de $\mathrm{Hg}$ e as alterações histopatológicas em órgãos da espécie Trichiurus lepturus (peixe-espada), assim como verificar o grau de contaminação mercurial em peixes comercializados na praia de Itaipu, Niterói, Rio de Janeiro (RJ) a fim de contribuir com informações relevantes à comunidade científica e avaliar os riscos para a saúde da população em geral.

\section{MATERIAL E MÉTODOS}

Foram analisados 31 exemplares da espécie Trichiurus lepturus (peixe-espada), capturados no período entre dezembro de 2005 e novembro de 2006 , na praia de Itaipu, Niterói, RJ. Estes foram acondicionados em recipiente isotérmico com gelo e encaminhados ao Laboratório de Controle FísicoQuímico da Faculdade de Veterinária da Universidade Federal Fluminense (UFF).

Os exemplares foram pesados e mensurados e, em seguida, eviscerados para separação do rim e do cérebro e para a retirada do fragmento de musculatura estriada esquelética. Os órgãos foram pesados individualmente em balança analítica e fracionados em dois fragmentos: um para a análise dos níveis de $\mathrm{Hg}$ e o outro para a análise histopatológica. Para a primeira, os fragmentos foram acondicionados individualmente, identificados e estocados em freezer a $-25^{\circ} \mathrm{C}$. Para a segunda, os fragmentos foram colocados em frascos com formol a $10 \%$, sendo que, para cada exemplar de peixe, foi utilizado um frasco, devidamente identificado, onde foram colocados o rim e o tecido muscular. Os cérebros foram acondicionados em frascos com formol a $10 \%$ separadamente devido ao seu diminuto tamanho. Todos os procedimentos foram realizados no Laboratório de Controle Físico-Químico na Faculdade de Veterinária da UFF.

Para as análises histopatológicas, os fragmentos fixados em formol a $10 \%$ foram enviados para o laboratório de Anatomia Patológica, onde foram realizados os métodos rotineiros de desidratação, clarificação, impregnação, inclusão, montagem e coloração das lâminas em Hematoxilina-eosina (HE), segundo JUNQUEIRA \& CARNEIRO (1982). Para a captura das imagens, foi utilizada câmera digital Lumix da Panasonic, modelo DMC-FZ3-S.

Para a análise de $\mathrm{Hg}$, foi utilizada a técnica de espectrofotômetria de absorção atômica por arraste de vapor frio (EAA-VF), com o equipamento BACHARACH COLEMAN, modelo MAS - 50B, descrita por DEITZ et al. (1973) com pequenas modificações. Os resultados foram obtidos em microgramas de $\mathrm{Hg}$ por gramas da amostra $\left(\mu \mathrm{g} \mathrm{g}^{-1}\right)$, sendo o limite mínimo de detecção de $\mathrm{Hg}$ do equipamento utilizado $0,01 \mu \mathrm{g}$ e o limite máximo $9,0 \mu \mathrm{g}$ no material analisado.

O tratamento estatístico dos resultados constou de uma análise descritiva simples e de uma comparação das médias de concentração de Hg obtidas em cada tecido estudado, por análise de variância (ANOVA). Outra análise estatística utilizada foi o Coeficiente de Correlação de Pearson, em que foi medido o grau de correlação entre duas variáveis. O programa computacional utilizado foi SPSS 10.0 para Windows. 


\section{RESULTADOS E DISCUSSÃO}

Os valores de concentração de $\mathrm{Hg}$ obtidos em musculatura e rim de peixe-espada, peso do rim, bem como os dados biométricos dos exemplares estão apresentados na tabela 1. Estes valores foram inferiores aos encontrados por LIPARISI et al. (2000), que estudaram esta mesma espécie, na mesma região, com variação de 0,021 a $0,618 \mu \mathrm{g} \mathrm{g}^{-1}$, e média de $0,145 \pm 0,15 \mu \mathrm{g}$ $\mathrm{g}^{-1}$. Isso pode ser atribuído, ao menos em parte, à maior variação no comprimento total, pois o tamanho dos peixes variou de 100 a $164,5 \mathrm{~cm}$, enquanto no presente estudo o tamanho dos exemplares variou entre 74,00 $\mathrm{cm}$ e $134,00 \mathrm{~cm}$, sugerindo animais mais jovens e, portanto, menos expostos ao $\mathrm{Hg}$ ou ainda menor exposição ambiental ao metal. $\mathrm{O}$ valor médio de $\mathrm{Hg}$ encontrado na musculatura dos peixes utilizados neste estudo foi semelhante aos valores médios encontrados nas espécies predadoras do litoral fluminense analisadas por SELLANES et al. (2002), capturadas na costa fluminense, ao longo da costa de Cabo Frio até a divisa com o Estado do Espírito Santo, e por MEDEIROS (2006), em musculatura vermelha de albacoras (Thunnus albacares), também oriundas do litoral fluminense, próximo à plataforma de petróleo da cidade de Campos, RJ. Este fato pode ser atribuído à posição na cadeia trófica das espécies analisadas. Por outro lado, os valores foram bastante diferentes dos descritos por MÁRSICO et al. (2002), em que a concentração de $\mathrm{Hg}$ nos exemplares de $\boldsymbol{X}$. gladius variou entre $0,025 \mu \mathrm{g} \mathrm{g}^{-1}$ e $0,510 \mu \mathrm{g} \mathrm{g}^{-1}$, e a concentração de Hg nos exemplares

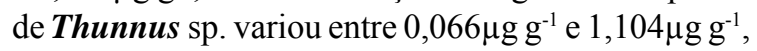

Tabela 1 - Comprimento total $(\mathrm{cm})$ e peso total $(\mathrm{g})$, concentração de Hg no músculo, peso do rim e concentração de Hg no rim dos exemplares de peixe-espada (Trichiurus lepturus) analisados.

\begin{tabular}{|c|c|c|c|c|c|}
\hline Amostras & comprimento total $(\mathrm{cm})$ & peso total (g) & Hg músculo ( $\left.\mu \mathrm{g} \mathrm{g}^{-1}\right)$ & peso rim $(\mathrm{g})$ & Hg rim $\left(\mu g g^{-1}\right)$ \\
\hline 1 & 130,0 & 1399,0 & 0,124 & 11,8 & 0,012 \\
\hline 2 & 119,5 & 1078,6 & 0,107 & 8,7 & 0,017 \\
\hline 3 & 109,0 & 752,5 & 0,045 & 5,0 & 0,008 \\
\hline 4 & 90,0 & 479,4 & 0,045 & 3,0 & 0,006 \\
\hline 5 & 96,0 & 614,2 & 0,038 & 4,2 & 0,007 \\
\hline 6 & 100,0 & 570,0 & 0,050 & 4,2 & 0,003 \\
\hline 7 & 121,0 & 984,4 & 0,050 & 6,8 & 0,010 \\
\hline 8 & 118,0 & 866,5 & 0,060 & 6,0 & 0,005 \\
\hline 9 & 121,5 & 1077,5 & 0,063 & 7,4 & 0,007 \\
\hline 10 & 100,5 & 516,4 & 0,030 & 2,7 & 0,022 \\
\hline 11 & 110,0 & 906,1 & 0,042 & 5,1 & 0,009 \\
\hline 12 & 106,0 & 904,4 & 0,032 & 5,8 & 0,010 \\
\hline 13 & 114,0 & 965,0 & 0,082 & 7,8 & 0,008 \\
\hline 14 & 116,0 & 1125,3 & 0,050 & 6,8 & 0,004 \\
\hline 15 & 110,5 & 790,0 & 0,063 & 5,0 & 0,004 \\
\hline 16 & 108,0 & 970,3 & 0,045 & 5,0 & 0,002 \\
\hline 17 & 121,0 & 1339,5 & 0,038 & 7,8 & 0,010 \\
\hline 18 & 83,5 & 229,3 & 0,010 & 1,7 & 0,004 \\
\hline 19 & 80,0 & 276,9 & 0,012 & 1,9 & 0,009 \\
\hline 20 & 82,0 & 304,6 & 0,015 & 1,5 & 0,003 \\
\hline 21 & 88,5 & 268,7 & 0,015 & 1,8 & 0,001 \\
\hline 22 & 87,0 & 378,0 & 0,023 & 2,5 & 0,001 \\
\hline 23 & 78,5 & 252,3 & 0,014 & 1,6 & 0,003 \\
\hline 24 & 74,0 & 239,4 & 0,010 & 1,5 & 0,004 \\
\hline 25 & 75,0 & 226,0 & 0,022 & 1,8 & 0,002 \\
\hline 26 & 123,0 & 1458,2 & 0,068 & 10,1 & 0,008 \\
\hline 27 & 122,5 & 1295,6 & 0,068 & 10,6 & 0,005 \\
\hline 28 & 134,0 & 1861,9 & 0,129 & 15,6 & 0,008 \\
\hline 29 & 122,5 & 1220,8 & 0,078 & 12,1 & 0,004 \\
\hline 30 & 129,5 & 1592,6 & 0,095 & 12,4 & 0,004 \\
\hline 31 & 125,0 & 1623,7 & 0,080 & 10,8 & 0,008 \\
\hline Valor mín & 74,0 & 226,0 & 0,010 & 1,5 & 0,001 \\
\hline Valor máx & 134,0 & 1861,9 & 0,129 & 15,6 & 0,022 \\
\hline Média \pm DP & $106,3 \pm 17,9$ & $857,0 \pm 466,2$ & $0,051 \pm 0,031$ & $6,1 \pm 3,8$ & $0,006 \pm 0,004$ \\
\hline
\end{tabular}

Ciência Rural, v.39, n.2, mar-abr, 2009. 
em exemplares oriundos da costa Sul do Brasil, entretanto, estas espécies são mais predadores, mais vorazes e alcançam tamanhos maiores. O resultado de Hg obtido em rim $\left(0,006 \pm 0,004 \mu \mathrm{g} \mathrm{g}^{-1}\right)$ foi bastante abaixo do encontrado por MEDEIROS em 2006, que verificou valores mais elevados em ambas as espécies estudadas (Thunnus albacares - 0,027 $\pm 0,018 \mu \mathrm{g} \mathrm{g}^{-1}$; Cynoscion microlepidotus - $\left.0,120 \pm 0,003 \mu \mathrm{g} \mathrm{g}^{-1}\right)$.

No "pool" de cérebro, o valor de $\mathrm{Hg}$ encontrado foi de $0,019 \mu \mathrm{g} \mathrm{g}^{-1}$, valor esse bem inferior ao encontrado por SHAW \& PANIGRAHI (1990) no mesmo órgão em estudo realizado em Arius nenga, Sillago sihama e Scatophagus argus. Os mesmos obtiveram valor máximo de $702 \pm 205 \mu \mathrm{g} \mathrm{g}^{-1} \mathrm{de} \mathrm{Hg}$ no tecido cerebral na espécie $\mathrm{S}$. sihama, possivelmente por tratar-se de estuário contaminado com altos teores de $\mathrm{Hg}$ a partir da descarga de efluentes de uma indústria de cloro-soda.

No presente estudo, assim como naquele de SELLANES et al. (2002), nenhum dos valores de $\mathrm{Hg}$ encontrados ultrapassou o limite máximo determinado pela legislação vigente (BRASIL, 1999). Entretanto, deve-se ressaltar a importância desses dados no caso de consumidores que se alimentem diariamente de produtos marinhos, devido ao caráter acumulativo do metal(WHO, 1990; YALLOUZ, 2002).

Os valores individuais mínimos e máximos de $\mathrm{Hg}$ encontrados na musculatura $\left(0,010\right.$ e $\left.0,129 \mu \mathrm{g} \mathrm{g}^{-1}\right)$ e no rim $\left(0,0007\right.$ e $\left.0,022 \mu \mathrm{g} \mathrm{g}^{-1}\right)$ demonstram uma ampla dispersão, fato também observado por BECKETT \& FREEMAN (1974) e MEDEIROS (2006) em exemplares de outras espécies analisadas.

Evidenciou-se uma correlação positiva altamente significativa entre comprimento total e teor de $\mathrm{Hg}$ em tecido muscular e peso total e teor de $\mathrm{Hg}$ $(\mathrm{r}=0,85 ; \mathrm{P}<0,001 ; \mathrm{r}=0,88 ; \mathrm{P}<0,001$, respectivamente). Estas mesmas correlações também foram evidenciadas por LIPARISI et al. (2000) na mesma espécie e na mesma região do presente estudo e por SELLANES et al. (2002), que analisaram diversas espécies de peixes do litoral fluminense, confirmando a teoria de bioacumulação a partir da exposição contínua do metal, citadas por WASSEMAN et al. (2001) e HOFFMAN et al. (2003).

Não foi evidenciada correlação significativa entre peso do rim e teor de $\mathrm{Hg}(\mathrm{r}=0,24 ; \mathrm{P}<0,19)$. Em peixes expostos ao $\mathrm{Hg}$ em laboratório, a concentração em baço, rim, fígado, cérebro e sangue tende a cair após a cessação da exposição e o músculo esquelético é o principal receptor desse metilHg redistribuído (WIENER \& SPRY, 1996). Esta propriedade pode estar gerando essa oscilação nos resultados e conseqüente ausência de correlação significativa entre peso e teor de $\mathrm{Hg}$.
Nos testes de comparação múltipla entre os teores de $\mathrm{Hg}$ de músculo, rim e cérebro, foi observada uma diferença altamente significativa entre $\mathrm{Hg}$ em músculo e $\mathrm{Hg}$ em rim, assim como para $\mathrm{Hg}$ em músculo e Hg em cérebro $(\mathrm{P}<0,001$ para ambos $)$. Na comparação entre $\mathrm{Hg}$ em rim e $\mathrm{Hg}$ em cérebro, também foi verificada uma diferença significativa ao nível de 5\% de probabilidade $(\mathrm{P}<0,05)$. BECKETT \& FREEMAN (1974) também observaram uma variação considerável nos teores médios de $\mathrm{Hg}$ em musculatura abdominal, rim e cérebro de Xiphias gladius, assim como MEDEIROS (2006) na análise de musculatura vermelha e rim em albacoras (Thunnus albacares). Estas ocorrências demonstram que o metal não se distribui uniformemente no organismo dos peixes. Todas as amostras analisadas no presente estudo apresentaram níveis de $\mathrm{Hg}$ abaixo dos valores determinados pela legislação vigente (BRASIL, 1999).

\section{Achados histopatológicos}

$\mathrm{Na}$ análise histopatológica, foi evidenciada alteração apenas no rim, onde foi observado um grande número de corpos melanomacrofágicos (Figura. 1) dispersos por todo o órgão de forma difusa e com coloração bastante escura, variando do marrom ao preto. BERNTSSEN et al. (2003), em análise experimental, detectaram um aumento da atividade de macrófagos atuando sobre os depósitos de $\mathrm{Hg}$ em rim de animais expostos. Da mesma forma, MELA et al. (2007) detectaram, nas análises morfológicas, grande número de centros melanomacrofágicos no fígado e no rim cranial. Diversos fatores, tais como outros poluentes, características da água e fisiologia animal podem estar determinando estes achados. AGIUS \& ROBERTS (2003) destacam que tais fatores aumentam com o tamanho do animal, em condições de estresse ambiental, e podem se desenvolver em associação a lesões inflamatórias crônicas, este último também citado por CARDOSO et al. (2004).

Nesse mesmo órgão, também foram observadas, em alguns animais, formações circulares cartilaginosas e bem delimitadas (Figura 1) em diferentes estágios de desenvolvimento no interior do parênquima renal. Tais lesões são classificadas como metaplásicas, que significa a transformação de um tecido adulto normal, completamente diferenciado, em outro tipo de tecido adulto relacionado (THOMSON, 1983). Dos 31 exemplares analisados, seis apresentaram metaplasia cartilaginosa, demonstrando uma prevalência de 19,35\% entre os indivíduos. Além disso, foi observada, entre os acometidos, uma variação no peso total de $614,20 \mathrm{~g}$ a $1861,90 \mathrm{~g}$ e no comprimento total de $96,00 \mathrm{~cm}$ a $134,00 \mathrm{~cm}$, ou seja, os animais de 


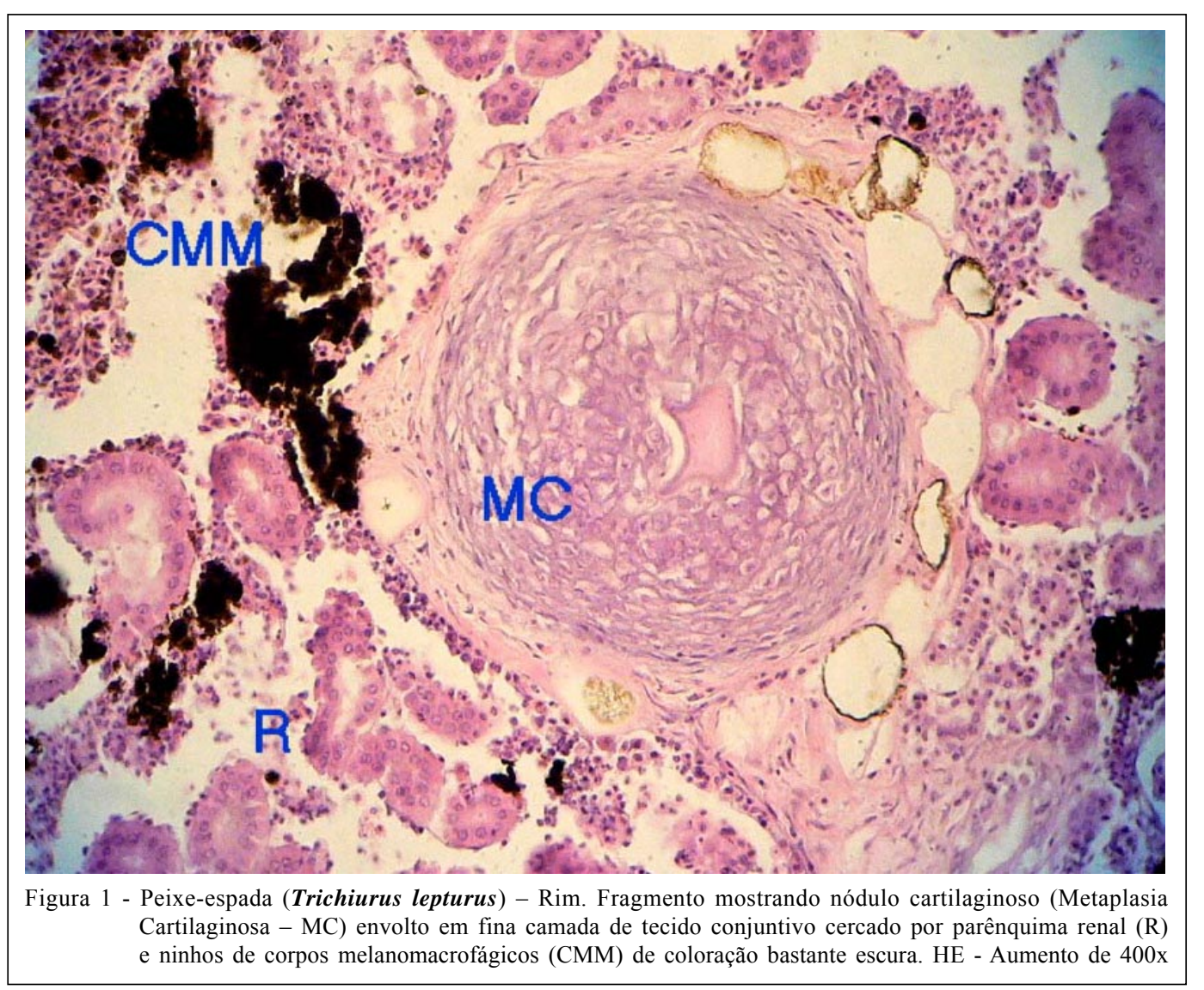

maior peso e comprimento. CHEVILLE (2004) descreve que este processo representa a substituição de células vulneráveis por células mais resistentes a um estresse estimulado e que, como na hiperplasia, é uma forma de crescimento celular anormal, controlada e reversível, sendo esta alteração ordenada, com fiel reprodução do novo tipo celular. A metaplasia desenvolve-se por uma reprogramação genética de células-tronco indiferenciadas e quase sempre aparece em órgãos em processo de atrofia. Este mesmo tipo de lesão também foi observado por ANDRADA et al. (2003) nesta mesma espécie de peixe, capturada na mesma região. Segundo os autores, a metaplasia pode estar associada a uma reação inflamatória granulomatosa que pode ser ocasionada por infecções parasitárias ou bacteriológicas (bactérias álcool-ácido resistentes). Estudo sobre o efeito teratogênico do selênio realizado em embriões da espécie Pogonichthys macrolepidotus demonstrou que os peixes expostos apresentaram edema de pericárdio, deformidades esqueléticas (como perda de cauda, lordose, escoliose etc.) e alterações histológicas como displasia, hiperplasia e metaplasia de tecidos esqueléticos nos peixes deformados (TEH, et al., 2002).
Em diversos estudos como os realizados por BANERJEE \& BHATTACHARYA(1994), BERNTSSEN et al. (2003) e MELA et al. (2007), foram observadas alterações consideradas bastante graves, como edema, degeneração, necrose, entre outras, nos órgãos e tecidos analisados. Nenhuma dessas lesões foi evidenciada no presente estudo.

\section{CONCLUSÕES}

Houve correlação positiva altamente significativa entre o comprimento total e o teor de $\mathrm{Hg}$ em tecido muscular e o peso total e o teor de Hg. Não foi observada uma correlação significativa entre os valores de $\mathrm{Hg}$ no rim e no peso desse órgão. Houve ampla dispersão dos valores médios de $\mathrm{Hg}$ entre os órgãos e os tecidos analisados. No músculo foram observadas as maiores concentrações de $\mathrm{Hg}$, seguido do cérebro e do rim. Os teores de $\mathrm{Hg}$ encontrados nos três órgãos se apresentaram bem abaixo dos limites máximos permitidos pela legislação.

Os achados histopatológicos observados no rim não foram considerados graves e não tem relação com a contaminação por mercúrio, cuja concentração 
foi pequena nos peixes comercializados na praia de Itaipu, Niterói, RJ. Entretanto, mesmo não sendo observados valores para a concentração de $\mathrm{Hg}$ maiores que os indicados na legislação brasileira, é de extrema importância a monitorização dessa espécie analisada a fim de garantir a qualidade do pescado, tendo em vista a sua importância para a saúde pública.

\section{REFERÊNCIAS}

AGIUS, C.; ROBERTS, R.J. Melano-macrophage centers and their role in fish pathology. Journal of Fish Diseases, v.26, p.499-509, 2003

ANDRADA, C.D.G. et al. Metaplasia cartilaginosa renal em espada Trichiurus lepturus L.(Teleostei: Trichiuridae) Brazilian Journal of Veterinary Science, v.10, n.3, p.191192, 2003.

BANERJEE, S.; BHATTACHARYA, S. Histopathology of kidney of Channa puntactus exposed to chronic nonlethal level of Elsan, Mercury and Ammonia. Ecotoxicology and Environmental Safety, v.29, p.265-275, 1994.

BECKETT, J.S.; FREEMAN, H.C. Mercury in Swordfish and other pelagic species from Western Atlantic Ocean. In INTERNATIONAL BILLFISH SYMPOSIUM, 1974, Hawai, Proceedings... Kailua-Kona: NOAA, 1974. Technical Report NMFS SSRF-675, Pt. 2. p.154-159.

BERNTSSEN, M.H.G. et al. Chronic dietary mercury exposure causes oxidative stress, brain lesions, and altered behaviour in Atlantic salmon (Salmo salar) parr. Aquatic Toxicology, v.65, n.1, p.55-72, 2003.

BISINOTI, M.C.; JARDIM, W.F. O comportamento do Metilmercúrio (MetilHg) no ambiente. Química Nova, v.27, n.4, p.593-600, 2004.

BRASIL. Ministério da Agricultura Pecuária e Abastecimento. Instrução Normativa n. 42, de 20 de dezembro de 1999. Aprova a estrutura regimental do Ministério da Agricultura, e dá outras providências. Diário Oficial da República Federativa do Brasil, Brasília, DF, 1999.

CARDOSO, T.P. et al. Avaliação histológica de centros melanomacrofágicos em corvinas (Micropogonias furnieri) capturados na praia de Itaipu - Niterói, RJ. In: JORNADA DE MEDICINA VETERINÁRIA DA UNIPAR, 9.; MOSTRA CIENTÍFICA EM MEDICINA VETERINÁRIA, 6., 2004, Umuarama. Resumos... Umuarama: Arquivos de Ciências Veterinárias e Zoologia da Unipar, 2004. V.7, n.1, p.88.

CARPI, A. The toxicology of mercury. 2001. Acesso em: 15 fev. 2007. On line. Disponível em: <http:// www.albuw.ait.ac.th/Group_R/Mercury/report4/ m e r c u r y a b a t e me n t $_{-} 4 \mathrm{th} / \mathrm{pdf}_{-} 1 \mathrm{ink} /$ Toxicology $\% 20$ of $\% 20 \mathrm{Hg}$.pdf $>$

CHEVILLE, N.F. Introdução à patologia veterinária. 2.ed. São Paulo: Roca, 2004. p.334.
DEITZ F.D.;et al. Metals and others elements - Rapid, sensive method for determination variety of biological samples. Journal of the Association of Official Analytical Chemistis. v.56, p.378-382, 1973.

ENSEADA de Jurujuba é uma das mais poluídas do mundo. Jornal O Globo, Rio de Janeiro, 22 jan. 2006. Acesso em 13 fev. 2007 On line. Disponível em: <http:// www.jornaldomeioambiente.com.br/JMA-Jurujuba// poluicao.asp>

FERREIRA, M.S. Contaminação mercurial em pescado capturado na Lagoa Rodrigo de Freitas - Rio de Janeiro. 2006. 100f. Dissertação (Mestrado em Medicina Veterinária Higiene Veterinária e Processamento Tecnológico de Produtos de Origem Animal) - Universidade Federal Fluminense, Niterói, RJ.

HOFFMAN, D.J. et al. (Ed.). Handbook of ecotoxicology. 2.ed. Boca Raton: Lewis Publishers, 2003. Cap.16, p. 409463.

JUNQUEIRA, L.C.; CARNEIRO, J. Histologia básica. 5.ed. Rio de Janeiro: Guanabara Koogan, 1982. 533p.

LIPARISI, F. et al. Determinação dos teores de mercúrio em amostras de peixe-espada (Trichiurus lepturus), coletadas na praia de Itaipu - Niterói, RJ. Higiene Alimentar, v.14, n.77, p.37-39, 2000.

LODENIUS, M.; MALM, O. Mercury in the Amazon. Review of Environmental Contamination and Toxicology. v.157, p.25-52, 1998.

MÁRSICO, E.T. et al. Evaluation of mercury contamination in two species of fish caught in south Brazilian coast. In: XVIII CONGRESSO PANAMERICANO DE CIENCIAS VETERINARIAS, 18., 2002, La Habana, Cuba. Anais...La Habana, 2002, n.841.

MARTINS, A.S.; HAIMOVICI, M. Distribution, abundance and biological interactions of the cutlassfish Trichiurus lepturus in the southern Brazil subtropical convergence ecossystem. Fisheries Research, v.30, p.217-227, 1997.

MEDEIROS, R.J. Distribuição do metal mercúrio em atum (Thunnus albacares) e pescada bicuda (Cynoscion microlepidotus) capturados no litoral do Rio de Janeiro, Brasil. 2006. 90f. Dissertação (Mestrado em Medicina Veterinária - Higiene Veterinária e Processamento Tecnológico de Produtos de Origem Animal) - Universidade Federal Fluminense.

MELA, M. et al. Effects of dietary methylmercury on liver and kidney histology in the neotropical fish Hoplias malabaricus. Ecotoxicology and Environmental Safety, v.68, p.1, 2007.

SELlAnes, A.G. et al. Mercúrio em peixes marinhos. Acta Scientiae Veterinariae, v.30, n.2, p.107-112, 2002.

SHAW, B.P.; PANIGRAHI, A.K. Brain AChE activity studies in some fish species collected from a mercury contaminated

Ciência Rural, v.39, n.2, mar-abr, 2009. 
estuary. Water, Air and Soil Pollution, v.53, p.327-334, 1990.

TEH, S.J. et al. Selenium-induced teratogenicity in Sacramento splittail (Pogonichthys macrolepidotus) Marine Environmental Research, v.54, n.3-5, p.605-608, 2002.

THOMSON, R.G. Patologia geral veterinária. Rio de Janeiro: Guanabara Koogan, 1983. 412p.

WASSERMAN, J. et al. O ciclo do mercúrio o ambiente Amazônico. Mundo e Vida, v.2, n.1-2. p.46-53, 2001.
WIENER, J.G.; SPRY, D.J. Toxicological significance of mercury in fresh water fish. In BEYER, W.N. et al. Environment contaminants in wildlife: interpreting tissue concentrations. Boca Raton: Lewis Publishers, 1996. Cap.13, p.297-339.

WHO. Environmental Health Criteria 101: Methylmercury. Geneva: World Health Organization, 1990. $144 \mathrm{p}$.

YALLOUZ, A. et al. Semiquantitative mercury determination in fish: a tool for poisoning prevention. Anais da Academia Brasileira de Ciência, v.74, n.1, p.187-191, 2002. 